Article

\title{
Study on Non-Bragg Microwave Backscattering from Sea Surface Covered with and without Oil Film at Moderate Incidence Angles
}

\author{
Honglei Zheng ${ }^{1, *}$, Jie Zhang ${ }^{1,2}$, Ali Khenchaf ${ }^{3}$ and Xiao-Ming Li ${ }^{4}$ (D) \\ 1 College of Oceanography and Space Informatics, China University of Petroleum (East China), \\ Qingdao 266580, China; zhangjie@fio.org.cn \\ 2 First Institute of Oceanography, Ministry of Natural Resources, Qingdao 266061, China \\ 3 Lab-STICC, UMR CNRS 6285, ENSTA Bretagne, 29806 Brest, France; ali.khenchaf@ensta-bratagne.fr \\ 4 Key Laboratory of Digital Earth Science, Aerospace Information Research Institute, Chinese Academy of \\ Sciences, Beijing 100094, China; lixm@radi.ac.cn \\ * Correspondence: hongleizheng@upc.edu.cn
}

Citation: Zheng, H.; Zhang, J.;

Khenchaf, A.; Li, X.-M. Study on

Non-Bragg Microwave

Backscattering from Sea Surface Covered with and without Oil Film at Moderate Incidence Angles. Remote

Sens. 2021, 13, 2443. https://doi.org/ $10.3390 / \mathrm{rs} 13132443$

Academic Editor: Merv Fingas

Received: 9 May 2021

Accepted: 21 June 2021

Published: 22 June 2021

Publisher's Note: MDPI stays neutral with regard to jurisdictional claims in published maps and institutional affiliations.

Copyright: (c) 2021 by the authors. Licensee MDPI, Basel, Switzerland. This article is an open access article distributed under the terms and conditions of the Creative Commons Attribution (CC BY) license (https:// creativecommons.org/licenses/by/ $4.0 /)$.

\begin{abstract}
In the past decades, Bragg scattering has been considered to be an important scattering mechanism of microwave backscattering from sea surfaces. However, as reported in many recent literatures, non-Bragg scattering (which is often attributed to wave breaking) also makes a significant impact on radar scattering, especially for Horizontal-Horizontal (HH) polarized radar signals. To date, we know far less about non-Bragg scattering than Bragg scattering. Herein, this paper carries out an investigation on non-Bragg scattering and its effect on radar echoes at moderate incidence angles, both for oil-free and oil-covered sea surfaces. This paper firstly presents a systematic comparison of several sea spectra commonly used for the simulation of microwave scattering from sea surfaces. It is found that none of them perform well for the description of Bragg waves. Then, the "pure" Bragg wave spectra are inverted in the framework of the two-scale model (TSM) and geophysical model functions (GMFs). The normalized radar cross sections (NRCS) related to total scattering, non-Bragg scattering, and "pure" Bragg scattering in C, X, and Ku-bands are simulated under various conditions (i.e., incidence angles, wind speeds, and wind directions). Quantitative assessments of the relative contributions of non-Bragg scattering to total scattering are conducted. We also perform a survey on the non-Bragg scattering from the oil-covered sea surface. This article provides some new insights for a better understanding of the non-Bragg microwave scattering from rough sea surfaces at moderate incidence angles.
\end{abstract}

Keywords: microwave scattering; ocean remote sensing; Bragg scattering; non-Bragg scattering; oil spill

\section{Introduction}

Microwave radars play an increasingly important role in ocean observation thanks to their capability of providing valuable data under all-weather, all-day, and all-night conditions. The emitted microwaves with a certain frequency from radars can interact with sea surface (or targets on the sea surface) to produce scattered microwaves, which could be detected and received again by radars for ocean observation. The normalized radar cross section (NRCS) or scattering coefficient as a parameter to describe the scattering strength is highly sensitive to the ocean-surface roughness induced by gravity-capillary surface waves, which can be influenced by various factors, such as the strength of local wind, the surfactant floating on the sea surface, etc. [1].

In the past decades, Bragg resonance has been broadly investigated and identified as an important mechanism of microwave backscattering from sea surface when the electromagnetic (EM) waves are in resonance with sea waves of comparable wavelengths [2]. 
However, it has been mentioned in many publications that the resonant Bragg mechanism is unable to fully describe the EM scattering of the sea surface [3-6]. At moderate incidence angles, the results predicted by the Bragg scattering model can match well with observations for vertical transmit vertical receive (VV) polarization. However, the prediction is not in agreement with observations for horizontal transmit horizontal receive $(\mathrm{HH})$ polarization [4-7]. Even the composite surface theory considering the large-wave tilting does not remove this discrepancy between the simulation and the observation at $\mathrm{HH}$ polarization [8,9]. The possible reason for this is that non-Bragg scattering induced by steep waves and wave breaking plays a significant role in this process [1,4]. Although various explanations for non-Bragg scattering (including scattering from breaking waves or near-breaking waves, quasi-specular scattering from steep wave fronts, etc.) have been proposed, the modeling of non-Bragg scattering mechanisms and its impact on microwave scattering from sea surfaces are still not well understood.

The frequent occurrence of wave breaking and its special radar echoes has stimulated numerous studies to determine the underlying physical mechanisms of these phenomena. Kwoh and Lake [10] studied the X-band microwave scattering from breaking waves at moderate incident angles, including edge diffraction effects and specular scattering. A phenomenological model for describing the mechanism of non-Bragg scattering was proposed by Phillips [11], which pointed out that the contribution of wave breakage to NRCS is independent of specular reflection, edge scattering, or scattering from the rough surface of the broken wave. Melville et al. [12] and Loewen [13] measured the backscattering of the X-band microwave wave on breaking waves at an incident angle of $65^{\circ}$ and found that the backscattering is significantly enhanced in wave fronts of the breaking waves due to the specular reflection on the steep wave fronts. Soon after, Voronovich and Zavorotny proposed a semi-empirical model to simulate the specular scattering from steep breaking waves [6]. Kudryavtsev et al. derived a semi-empirical model based on Phillips' model, further confirmed the major influence of wave breaking on the NRCS [1]. Recently, their further study on the backscattering from breaking waves demonstrated that the contribution of breaking waves to the total C-band radar backscatter can reach approximately $60-70 \%$ for $\mathrm{HH}$ and vertical transmit horizontal receive $(\mathrm{VH})$ polarization under all incidence angles [4]. Notably, even though wave breaking plays a dominant role in non-Bragg scattering, other factors (e.g., bound waves [14], sea droplets [15], sea surface curvature [5], sea foam [16], etc.) could also yield a similar impact on the scattering field. Although in the past several decades the study of microwave scattering from sea surface has made significant progress, the effects of non-Bragg scattering under various incidence angles, wind directions, and wind speeds are still not well understood.

Here, this paper carries out a study on the effect of non-Bragg scattering on radar echoes at moderate incidence angles, both for clean and oil-covered sea surfaces. Firstly, the basic theory of microwave scattering from sea surfaces is briefly introduced in Section 2. Then, the simulation of Bragg scattering is studied in Section 3. The non-Bragg scattering from the sea surface (Section 4) and oil-covered sea surface (Section 5) are simulated and analyzed in detail. Finally, the corresponding conclusion and my perspectives are provided in Section 6.

\section{Modeling of Microwave Scattering from Sea Surface at Moderate Incidence Angles}

Typically, the total NRCS of the sea surface $\left(\sigma_{p p}^{t}\right)$ can be represented as the sum of specular scattering $\left(\sigma^{s p}\right)$, the "pure" Bragg scattering $\left(\sigma_{p p}^{B}\right)$ and the non-Bragg scattering $\left(\sigma^{n B}\right)$ from breaking waves $[1,4,17]$.

$$
\sigma_{p p}^{t}=\sigma^{s p}+\sigma_{p p}^{B}+\sigma^{n B}
$$

Subscript $p$ represents the horizontal $(\mathrm{H})$ or vertical $(\mathrm{V})$ polarization. According to radar observations, it is known that $\sigma^{s p}$ (as well as $\sigma^{n B}$ ) is independent of polarization, and $\sigma_{p p}^{B}$ depends on polarization. 
For small incidence angles, the relative contribution of specular scattering to total scattering is rather large $\left(\sigma^{s p} / \sigma_{p p}^{t} \approx 0.7 \sim 0.8\right)$ because specular scattering governs in this area. Since both $\sigma^{s p}$ and $\sigma^{n B}$ are independent of polarization, it is not easy to individually study the impact of non-Bragg scattering on total scattering. For large incidence angles, the influence of "shadow effect" on microwave scattering becomes remarkable, making it hard to investigate the characteristics of non-Bragg scattering. Hence, the analyses and discussions in this work are limited to moderate incidence angles.

For moderate incidence angles, the contribution of specular scattering to total scattering is so small that it can be neglected. Consequently, the total NRCS of the sea surface at moderate incidence angles can be expressed as the sum of Bragg scattering and non-Bragg scattering components as follows:

$$
\sigma_{p p}^{t}=\sigma_{p p}^{B}+\sigma^{n B}
$$

The "two-scale model (TSM)" or "composite model" is often employed to simulate Bragg scattering from sea surfaces [18]. According to the TSM, the small-scale waves related to Bragg scattering are super-imposed linearly on the long wave and are significantly affected by large-scale waves due to tilting modulations, hydrodynamic modulations, and the non-linearity of the surface slopes. Taking the modulation effect of large-scale waves into account, the TSM solution at moderate incidence angles $\left(\theta_{i}>30^{\circ}\right)$ can be represented as the first order of a Taylor expansion in the long wave slope [1,19]. The NRCS of "pure" Bragg scattering can be written as

$$
\sigma_{p p}^{B}=\frac{\pi}{\tan ^{4} \theta_{i}}\left|G_{p p}\right|^{2}\left(1+g_{p p} s_{i}^{2}\right) B\left(k_{w}, \phi\right)
$$

where $\theta_{i}$ is the incidence angle, $g_{p p}$ is the polarization-dependent coefficient,

$$
\begin{gathered}
G_{V V}=\frac{\left(\varepsilon_{r}-1\right) \times\left[\varepsilon_{r}\left(1+\sin ^{2} \theta_{i}\right)-\sin ^{2} \theta_{i}\right]}{\left[\varepsilon_{r} \cos \theta_{i}+\sqrt{\varepsilon_{r}-\sin ^{2} \theta_{i}}\right]^{2}} \\
G_{H H}=\frac{\varepsilon_{r}-1}{\left[\cos \theta_{i}+\sqrt{\varepsilon_{r}-\sin ^{2} \theta_{i}}\right]^{2}}
\end{gathered}
$$

$\varepsilon_{r}$ is the relative dielectric constant of seawater. The Bragg wavenumber $k_{w}=2 k_{i} \sin \theta_{i}, k_{i}$ is the radar wave number. $B\left(k_{w}, \phi\right)=B_{0}\left(k_{w}\right) \Phi\left(k_{w}, \phi\right)$ is the directional curvature spectrum, where $B_{0}\left(k_{w}\right)$ is the omni-directional part and $\Phi\left(k_{w}, \phi\right)=\frac{1}{2 \pi}(1+\Delta \cos 2 \phi)$ is the spreading function. The relationship between the directional curvature spectrum $B\left(k_{w}, \phi\right)$ and sea surface elevation spectrum $S\left(k_{w}, \phi\right)$ can be written as $B\left(k_{w}, \phi\right)=k_{w}^{4} S\left(k_{w}, \phi\right)$, and $\phi$ is the wave propagation direction referenced to the wind.

In Equation (3),

$$
\begin{gathered}
g_{V V}=\frac{\tan ^{4} \theta_{i}}{2\left|G_{V V}\right|^{2}} \frac{\partial^{2}}{\partial \theta_{i}^{2}}\left(\frac{\left|G_{V V}\right|^{2}}{\tan ^{4} \theta_{i}}\right) \\
g_{H H}=\frac{\tan ^{4} \theta_{i}}{2\left|G_{H H}\right|^{2}} \frac{\partial^{2}}{\partial \theta^{2}}\left(\frac{\left|G_{H H}\right|^{2}}{\tan ^{4} \theta_{i}}\right)+\frac{2}{\sin ^{2} \theta_{i}}\left|\frac{G_{V V}}{G_{H H}}\right| \frac{s_{n}^{2}}{s_{i}^{2}}
\end{gathered}
$$

where $s_{i}^{2}$ and $s_{n}^{2}$ are the mean square slope (MSS) of tilting waves in and out of the direction of the incidence plane.

According to the measurements from [20], slopes of waves in the slick covered areas (the scales of these waves correspond to the scales of tilting waves in TSM) are almost isotropic. Following [4], we assume that $s_{i}^{2}=s_{n}^{2}=s^{2} / 2$, and the MSS can be obtained by

$$
s^{2}=4.5 \times 10^{-3} \ln \left(\alpha^{-2} k_{d} U_{10}^{2} / g\right)
$$


where $k_{d}=k_{w} / 4$ is the dividing wavenumber in TSM, $\alpha=U_{10}\left(k_{p} / g\right)^{1 / 2}$ is the inverse wave age of wind seas, $U_{10}$ is the wind speed at $10 \mathrm{~m}$ height, $g$ is the gravity acceleration, and $k_{p}$ is the spectral peak wavenumber.

The NRCS of non-Bragg scattering can be derived from dual co-polarized NRCS,

$$
\sigma^{n B}=\sigma_{V V}^{t}-\frac{\sigma_{V V}^{t}-\sigma_{H H}^{t}}{1-p_{B}}
$$

where $p_{B}$ is estimated as the expected Bragg TSM polarization ratio (PR) value and it can be obtained by

$$
p_{B}=\frac{\left|G_{H H}\right|^{2}}{\left|G_{V V}\right|^{2}} \times \frac{1+g_{H H} \times s_{i}^{2}}{1+g_{V V} \times s_{i}^{2}}
$$

\section{On the Simulation of Bragg Scattering from Sea Surface}

\subsection{Impacts of Sea Spectrum on Microwave Bragg Scattering Simulation}

As expressed in Equation (3), to simulate the microwave Bragg scattering accurately, the primary task is to develop a spectral model accurate enough for modeling Bragg sea waves. To date, a number of sea spectra have been developed or proposed by different researchers [18,21-26]. This section aims at presenting a survey of some of the most common sea spectrum models in the application of microwave backscattering simulation. The performances based on these sea spectra in the simulation of microwave scattering have been reported in many literatures, e.g., $[9,27,28]$. However, the works mentioned above do not eliminate the impact of non-Bragg scattering. In the following, the difference of co-polarized NRCS (PD), i.e.,

$$
P D=\sigma_{V V}^{B}-\sigma_{H H}^{B}
$$

is simulated based on the TSM and various sea spectra, which eliminates the non-Bragg scattering component and is directly related to the Bragg wave spectrum [19,29].

On the other hand, in practical applications, to model the responses of incidence angle, wind speed, and wind direction on NRCS, various GMFs have been developed in the past decades, such as the NSCAT2 (NASA scatterometer) and the NSCAT4 for Ku-band [30], the XMOD2 (X-band model) for the X-band [31], the CMOD5N (C-band model) [32] and CMODH for the C-band [33], etc. GMFs are empirical models that were established based on a large amount of measured data, which could provide accurate predictions for microwave scattering from the sea surface. In this section, the newly developed CMODH [33] for the C-band and the NSCAT4 for the Ku-band, which can be utilized both for $\mathrm{HH}$ and $\mathrm{VV}$ polarization, were selected as references for comparisons.

Based on the spectrum proposed by Elfouhaily et al. (E spectrum) [21], the spectrum proposed by Hwang et al. (H spectrum) [22,23], the spectrum proposed by Romeiser et al. (R spectrum) [24], the spectrum proposed by Apel (A spectrum) [25], the spectrum proposed by Fung and Lee (F spectrum) [19], and the spectrum proposed by Pierson and Moskowitz (P spectrum) [26], the PD (without consideration of the contributions of nonBragg scattering) simulated by the TSM under various incidence angles, wind speeds, and wind directions are displayed in Figure 1, and was compared with those obtained by using GMFs. Please note that the TSM introduced in [18] rather than that obtained in Equation (3) was used in this simulation. The spreading function of the E spectrum is used for the $\mathrm{H}$ spectrum in this analysis. In Figure 1a, the results simulated by using the P spectrum, $F$ spectrum, and R spectrum are significantly larger than those of $\mathrm{CMODH}$, and the results simulated by using the $\mathrm{H}$ spectrum and A spectrum match well with CMODH. In Figure $1 \mathrm{~b}$, the results simulated by using the $\mathrm{E}$ spectrum and $\mathrm{H}$ spectrum are better than those of other spectra for Ku-band. In Figure 1c,d, the differences between GMFs and simulated results vary with wind direction. In general, the results simulated by using $\mathrm{E}$ spectrum and $\mathrm{H}$ spectrum agree better with GMFs than the other spectra. In Figure 1e,f, all of the curves increase with wind speed. For the C-band, the E spectrum, H spectrum, and A spectrum 
perform better than the other spectra. For Ku-band, the result of E spectrum matches well with NSCAT4. From Figure 1, it can be observed that there exist significant differences amongst the TSM and GMFs under different conditions, whatever sea spectra are adopted.
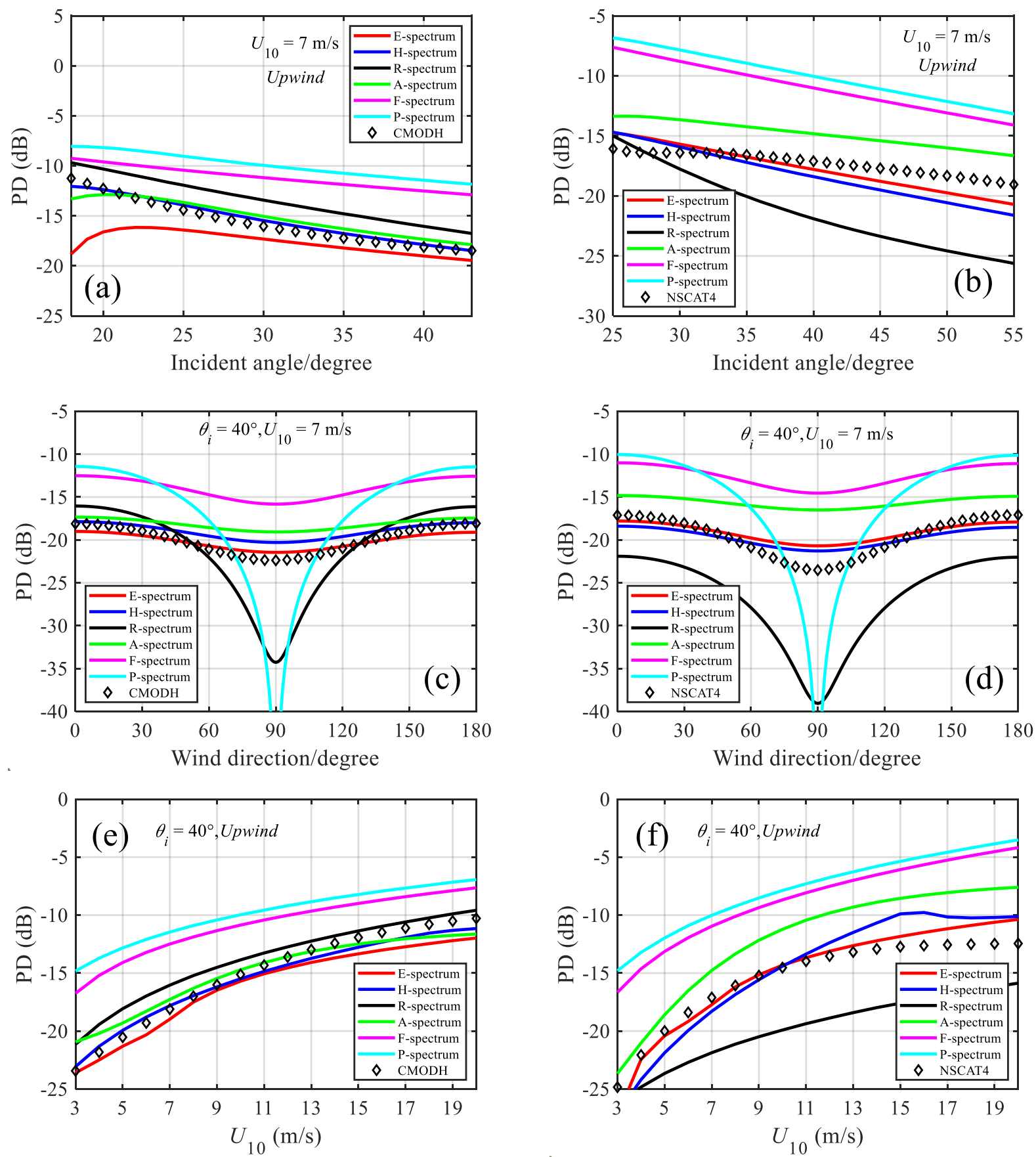

Figure 1. Comparisons of the PD simulated by using the TSM and GMFs for the C-band and Ku-band. (a,b): with respect to incidence angles, $(\mathbf{c}, \mathbf{d})$ : with respect to wind speeds; $(\mathbf{e}, \mathbf{f})$ : with respect to wind directions.

In fact, the differences between the NRCSs simulated by using the TSM and GMFs are induced by both the TSM and sea spectra. As the TSM is an asymptotic electromagnetic scattering model, the obtained results based on it inevitably have some errors. However, considering that the TSM has been extensively used in many literatures for estimating Bragg scattering component (e.g., $[4,29,34,35]$ ), we believe that the accuracy of Bragg 
scattering model is acceptable. Hence, the difference between the NRCSs simulated by using the TSM and GMFs is assumed to be induced by the inaccuracy of sea spectra.

\subsection{Inverting Bragg Waves Spectrum from GMFs}

According to the results from Figure 1, it can be demonstrated that the discrepancy between the measured and the simulated NRCS, is not only caused by the non-Bragg scattering, but also because of the inaccuracy of sea wave spectra. To gain a more accurate spectrum, in this section, the "pure" Bragg wave spectrum is inverted by using the TSM and GMFs.

The NRCS expressed with the GMF is generally written as [30]

$$
\sigma_{p p}^{G M F}=A_{0 p p}\left(\theta_{i}, U_{10}\right)+A_{1 p p}\left(\theta_{i}, U_{10}\right) \cos \phi+A_{2 p p}\left(\theta_{i}, U_{10}\right) \cos 2 \phi
$$

The isotropic term $A_{0 p p}\left(\theta_{i}, U_{10}\right)$, the upwind/downwind amplitude $A_{1 p p}\left(\theta_{i}, U_{10}\right)$, and the upwind/crosswind amplitude $A_{2 p p}\left(\theta_{i}, U_{10}\right)$ are all the functions of wind speed and incidence angle.

By comparing Equation (3) with Equation (12), the omnidirectional part of the curvature spectrum can be approximately calculated by using

$$
B_{0}\left(k_{w}\right)=\frac{2 \tan ^{4} \theta_{i}\left(A_{0 V V}-A_{0 H H}\right)}{\left|G_{V V}\right|^{2}\left(1+g_{V V} s_{i}^{2}\right)-\left|G_{H H}\right|^{2}\left(1+g_{H H} s_{i}^{2}\right)}
$$

and the $\Delta\left(k_{w}\right)$ in the spreading function can be calculated with

$$
\Delta\left(k_{w}\right)=\frac{2 \tan ^{4} \theta_{i}\left(A_{2 V V}-A_{2 H H}\right)}{B_{0}\left(k_{w}\right)\left[\left|G_{V V}\right|^{2}\left(1+g_{V V} s_{i}^{2}\right)-\left|G_{H H}\right|^{2}\left(1+g_{H H} s_{i}^{2}\right)\right]}
$$

As the NRCS of "pure" Bragg scattering expressed in Equation (3) cannot be used to simulate the asymmetry between upwind and downwind, we have omitted the second term in the right-hand of Equation (12).

Figure 2 presents the inverted omni-directional curvature spectrum obtained by using Equation (13) and the inverted $\Delta\left(k_{w}\right)$ gained by using Equation (14), and also compares with those obtained from $E$ spectrum. In this work, our study is limited to $C_{-}, X_{-}$, and $\mathrm{Ku}$-bands since there is a lack of a mature VV polarized GMF or a mature polarization ratio (PR) model for $\mathrm{L}$ band [36]. It should be noted that the XMOD2 is only valid for VV polarized channel. To estimate the NRCS in HH channel, a PR model for the X-band has been employed to convert the VV polarized NRCS to a HH polarized NRCS. In Figure 2a, it can be seen that there exist remarkable differences between the inverted sea spectrum and the E spectrum. In Figure 2b, as the wind speed increases, the $\Delta\left(k_{w}\right)$ of the E spectrum increases monotonically, while the inverted $\Delta\left(k_{w}\right)$ does not increase monotonically. For the $\mathrm{X}$-band, the value of $\Delta\left(k_{w}\right)$ is smaller than 0 when the wind speed is small enough. One can also note that there exists a significant inconsistency between the curves estimated by using XMOD2 and NSCAT4. The reason for this phenomenon is probably because the XMOD2 is a relatively new geophysical model and needs more time and data to be well-tuned. In this work, the inverted omni-directional curvature spectrum and $\Delta\left(k_{w}\right)$ can be regarded as "real" proxies of the Bragg wave spectrum. 

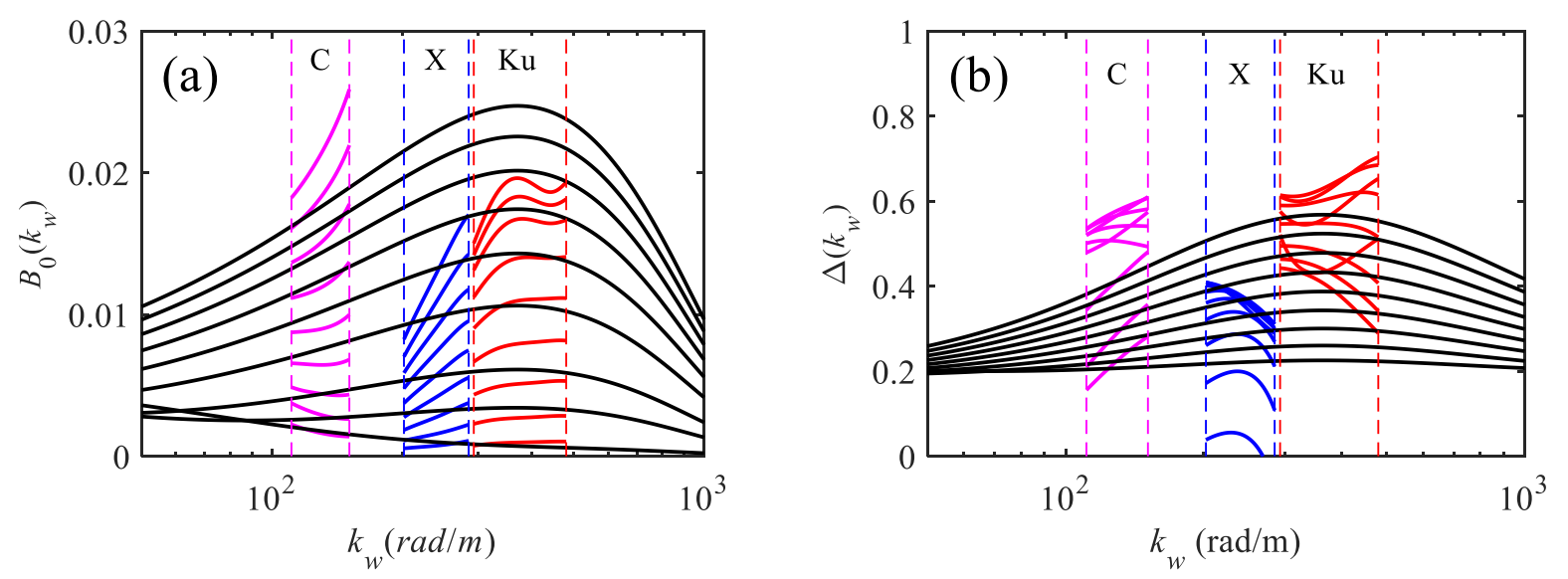

Figure 2. The inverted "pure" Bragg wave spectrum is compared with the E spectrum as wind speed ranges from $3 \mathrm{~m} / \mathrm{s}$ to $21 \mathrm{~m} / \mathrm{s}$ with a $2 \mathrm{~m} / \mathrm{s}$ step. (a) The omni-directional part of the curvature spectrum, and (b) the term $\Delta\left(k_{w}\right)$ in spreading function. The purple, blue, and red curves correspond to the region of $\mathrm{C}_{-}, \mathrm{X}-$, and $\mathrm{Ku}$-bands.

\section{On Non-Bragg Scattering from Sea Surface}

In order to understand the impacts of non-Bragg scattering on total scattering, in this section, the NRCSs of "pure" Bragg scattering and non-Bragg scattering under various incidence angles, wind speeds, wind directions, and radar frequencies will be simulated and studied. Substituting Equations (13) and (14) into Equation (3), the NRCS induced by "pure" Bragg scattering can be simulated. By using Equation (9), the NRCS induced by non-Bragg scattering can be obtained. Note that the NRCS of non-Bragg scattering in this paper is the same as the "non-polarized component (NP)" defined in [4]. To estimate the impact of non-Bragg scattering on total scattering, the relative contribution of non-Bragg scattering to total scattering (defined as the ratios of non-Bragg NRCS to total NRCS, i.e., $\left.\sigma^{n B} / \sigma_{p q}^{t}\right)$ is studied under various conditions.

Figure 3 displays the NRCSs of total scattering, "pure" Bragg scattering, and nonBragg scattering, and the relative contribution of non-Bragg scattering simulated by using the CMODH for different incident angles, wind directions, and wind speeds. In Figure $3 \mathrm{a}, \mathrm{b}$, the NRCS of non-Bragg scattering decreases with the incidence angle, which is similar to that of total scattering. The relative contribution of non-Bragg scattering for VV polarization decreases with incidence angles and almost does not change for $\mathrm{HH}$ polarization. Based on C-band fully polarized Radarsat-2 SAR data, Kudryavtsev et al. also investigated the relative contribution of non-Bragg scattering on radar return. The results shown in Figure $3 a, b$ are consistent with those presented in [4]. In Figure 3c, the non-Bragg scattering has its largest value in the upwind direction (corresponds to $0^{\circ}$ ) and has its smallest value in the downwind direction (corresponds to $180^{\circ}$ ). In the simulation of the "pure" Bragg wave spectrum (in Equations (13) and (14)), the upwind/downwind asymmetric term (the second term in the right hand of Equation (12)) has been omitted, leading to the same NRCS of "pure" Bragg scattering in upwind (0 deg) and downwind (180 deg) directions. The upwind/downwind asymmetric of total scattering has been totally "fall on" the nonBragg scattering. Therefore, errors may be introduced when simulating the non-Bragg scattering under various wind directions. In other words, the difference in the upwind and downwind direction of non-Bragg scattering in real cases maybe not as significant as it has been shown in Figure 3c. Moreover, by observing Figure 3d, we know that the relative contribution of non-Bragg scattering reaches its largest value in the crosswind. In Figure 3e, the NRCS of non-Bragg scattering increases with wind speed, which is similar to that of the total scattering and Bragg scattering. Meanwhile, in Figure 3f, the relative contribution of non-Bragg scattering is almost independent of wind speed, which implies that non-Bragg/Bragg is almost constant under different wind speeds. 

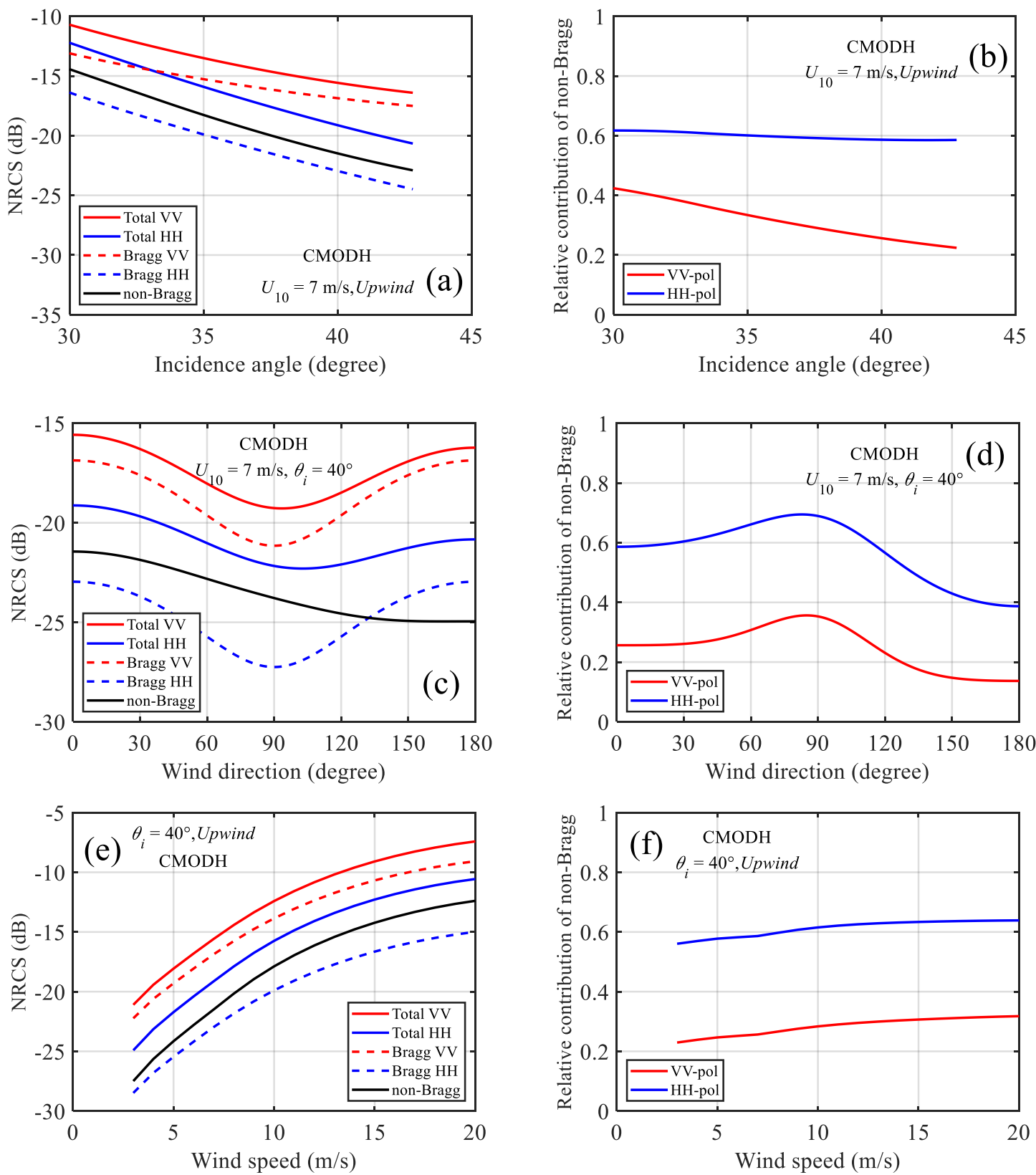

Figure 3. The NRCSs of total scattering, "pure" Bragg wave scattering and non-Bragg scattering, and the relative contribution of non-Bragg scattering estimated by using the CMODH. $(\mathbf{a}, \mathbf{b})$ : with respect to incidence angles, $(\mathbf{c}, \mathbf{d})$ : with respect to wind directions, (e,f): with respect to wind speeds.

Figure 4 shows the corresponding results simulated by using XMOD2 and PR model. In Figure $4 a$, under different incident angles, the non-Bragg scattering is significantly larger than both HH polarized and VV polarized "pure" Bragg scattering NRCS, which is different from that of the results exhibited in Figure 3. In Figure $4 b$, the relative contribution of non-Bragg scattering is larger than $60 \%$ for VV polarization, while it approaches $90 \%$ for $\mathrm{HH}$ polarization. By comparing the non-Bragg scattering relative contribution of the X-band (shown in Figure 4b) with that of the C-band (shown in Figure 3b) and Ku-band (shown in Figure 5b), the non-Bragg scattering relative contribution of X-band is supposed to be about $60 \sim 80 \%$ for $\mathrm{HH}$ polarization. However, as shown in Figure $4 \mathrm{~b}$, the relative contribution of non-Bragg scattering approaches $90 \%$ for $\mathrm{HH}$ polarization. The reason for this phenomenon may be that the non-Bragg scattering relative contribution of the X-band may have been overestimated. From Figure $4 c$, the non-Bragg scattering curve has similar 
behavior to the total scattering curve. In Figure $4 \mathrm{~d}$, the relative contribution of non-Bragg scattering is almost independent of wind directions, which is significantly different from the results shown in Figures 3 and 5. From Figure 4e,f, the non-Bragg scattering increases with wind speed while the relative contribution of non-Bragg scattering to total scattering almost independent of wind speeds, which are similar to that of C-band. In fact, the results simulated by using XMOD2 suffer a drawback, namely that the simulated results involve a polarization ratio model, while there is not a widely accepted accurate PR model at present. Hence, the results estimated by using the XMOD2\&PR maybe not as good as that of CMODH and NSCAT4.
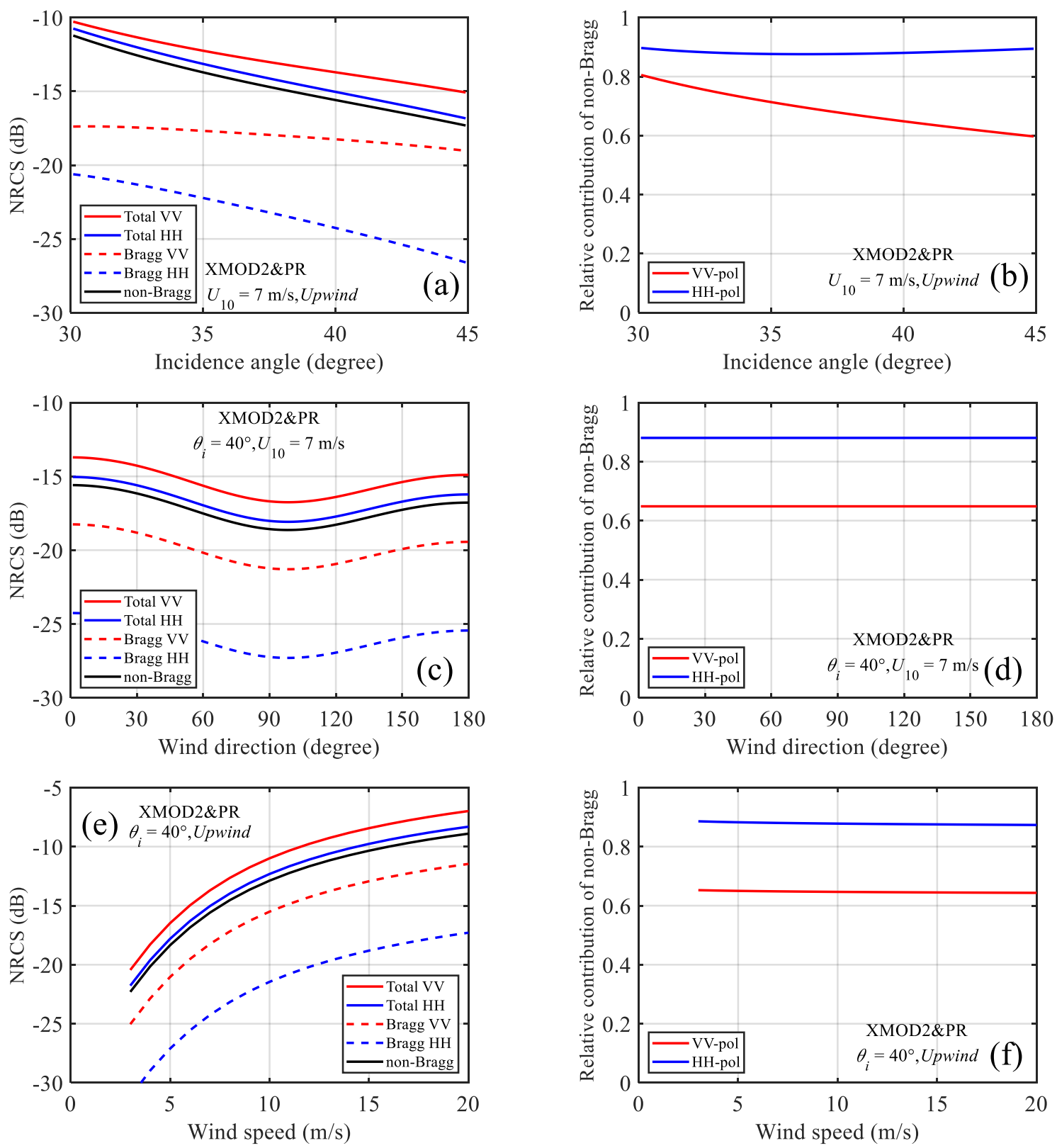

Figure 4. The NRCSs of total scattering, "pure" Bragg wave scattering and non-Bragg scattering, and the relative contribution of non-Bragg scattering estimated by using the XMOD2 and PR model. $(\mathbf{a}, \mathbf{b})$ : with respect to incidence angles, (c,d) with respect to wind directions, $(\mathbf{e}, \mathbf{f})$ : with respect to wind speeds. 

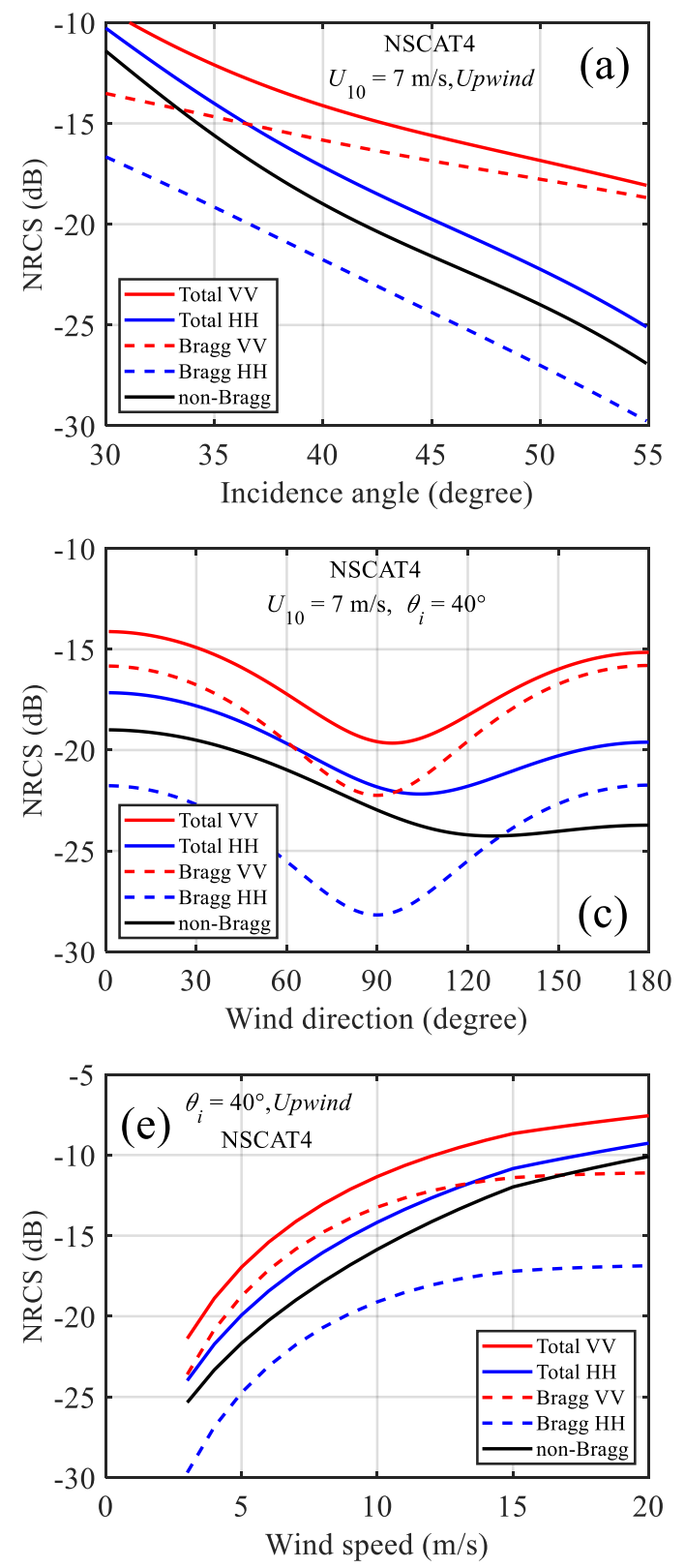
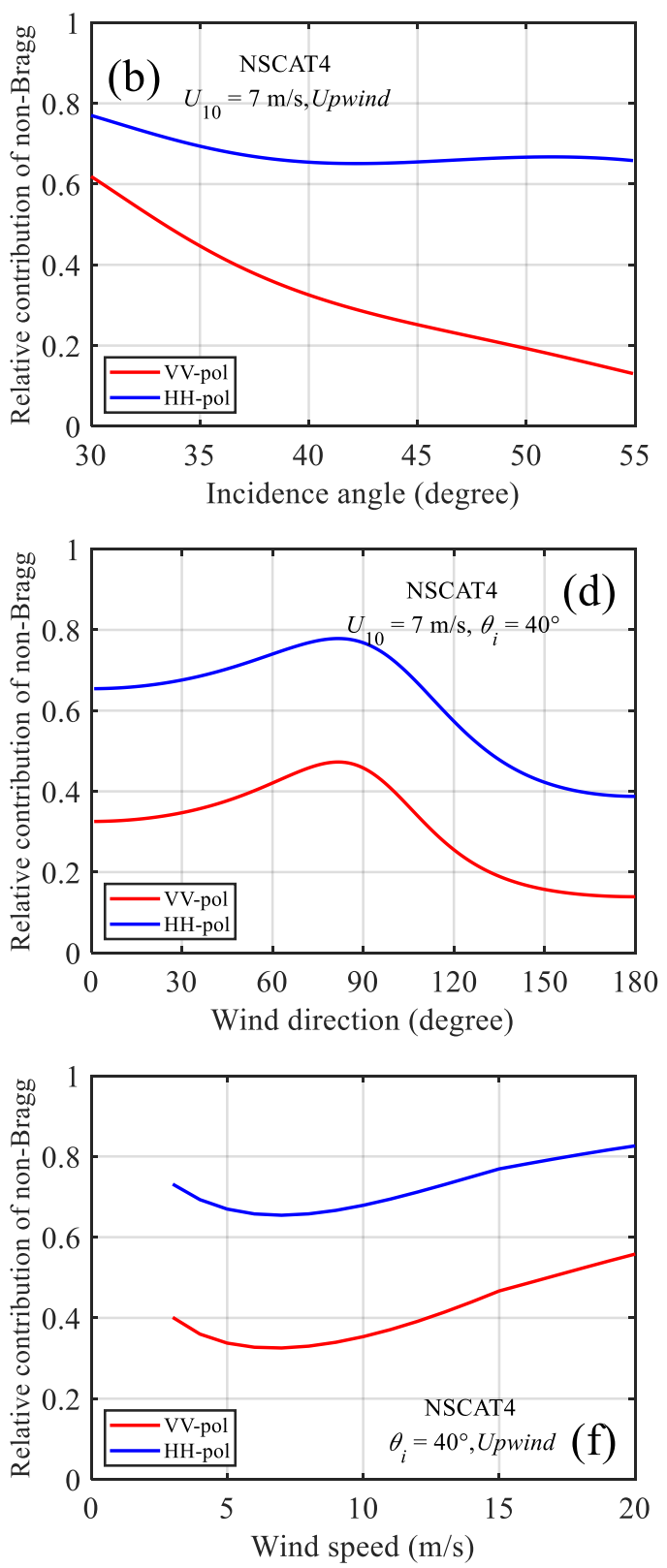

Figure 5. The NRCSs of total scattering, "pure" Bragg wave scattering and non-Bragg scattering, and the relative contribution of non-Bragg scattering estimated by using the NSCAT4. $(\mathbf{a}, \mathbf{b})$ : with respect to incidence angles, $(\mathbf{c}, \mathbf{d})$ : with respect to wind directions, (e,f): with respect to wind speeds.

The NRCS of total scattering, "pure" Bragg scattering, non-Bragg scattering, and the relative contribution of non-Bragg scattering simulated by using the NSCAT4 are presented in Figure 5. Under different incident angles, the NRCS of non-Bragg scattering at the $\mathrm{Ku}$-band has similar behavior with that of the C-band (as shown in Figure 3a). With the increase of incident angles, the relative contribution of non-Bragg scattering is about $70 \%$ for VV polarization, while it decreases from $60 \%$ to $20 \%$ for $\mathrm{HH}$ polarization (Figure $5 \mathrm{a}, \mathrm{b}$ ). For wind direction dependences (Figure 5c,d), the relative contribution of non-Bragg scattering reaches its largest value in crosswind direction. The relative contribution of non-Bragg scattering in the upwind direction is slightly larger than that in the downwind direction. From Figure 5e,f, the relative contribution of non-Bragg scattering does not exhibit significant dependence on wind speed, which is similar to that of the C-band (shown in Figure 3f). 
As mentioned above, the results simulated by XMOD2 are significantly different from those of CMODH and NSCAT4, which can be attributed to the inaccuracy of PR models used for XMOD2. The PR model used in the XMOD2 assumes that there is no wind speed dependence and wind direction dependence, but in actuality the effect of wind speeds and wind directions on PR cannot be neglected [37]. Therefore, the results estimated by using the CMODH and NSCAT4 are relatively more accurate and convincing.

It is known that the breaking wave coverage increases with wind speed [38]. As expected, in Figures $3 f$ and $5 f$, the non-Bragg scattering caused by breaking waves highly dependent on wind speed. However, the relative contribution of non-Bragg scattering (the ratio of non-Bragg scattering to total scattering) almost independent of wind speed, implying that the Bragg scattering and non-Bragg scattering increase in the same proportion with wind speed.

Moreover, by comparing Figures 3 and 5, one can note that the NRCS of non-Bragg scattering and the relative contribution of non-Bragg scattering of the C-band are significantly smaller than that of the Ku-band. Hence, we can reasonably conclude that the effect of non-Bragg scattering is more remarkable for higher frequency radar waves.

\section{On Non-Bragg Scattering from Oil-Covered Sea Surface}

It is of great significance to study the microwave scattering mechanisms from oilcovered sea surface for oil spill detection. The scattering mechanism of oil-covered sea surface has been studied in the literature theoretically as well as experimentally (see, e.g., $[29,34,35]$, and references therein). The presence of surfactant films on the surface of the sea resulted in significant suppressions of both the small-scale non-Bragg component and the Bragg component [29,35]. Through analysis of the slick contrasts of the total NRCS, Bragg and non-Bragg components, it was found that the non-Bragg scattering slick contrast values and their dependence on the wave number and on the azimuth angle are quite similar to the Bragg scattering, indicating that the oil film significantly influences the processes of wave breaking. It is also found that the modification of the micro-breaking of $\mathrm{cm}$-dm-scale waves in slicks can play the most important role in non-Bragg contrasts in slicks [34]. In this part, we will perform a further study on the non-Bragg scattering from the oil-covered sea surface by analyzing the relative contribution of non-Bragg scattering to total scattering. The Radarsat-2 data used in this part (as shown in Figure 6) was acquired during the oil spill experiment conducted by the Norway Clean Seas Association for Operating Companies (NOFO) in the North Sea [39], where the acquisition time is 17:27 (UTC) on 8 June 2011 and the incident angle is about $34.5^{\circ} \sim 36.1^{\circ}$. The wind speed is $1.6 \sim 3.3 \mathrm{~m} / \mathrm{s}$, which was observed by ships participating in the exercise and the closest oil platform. For more details about the field experiments, please refer to [39].

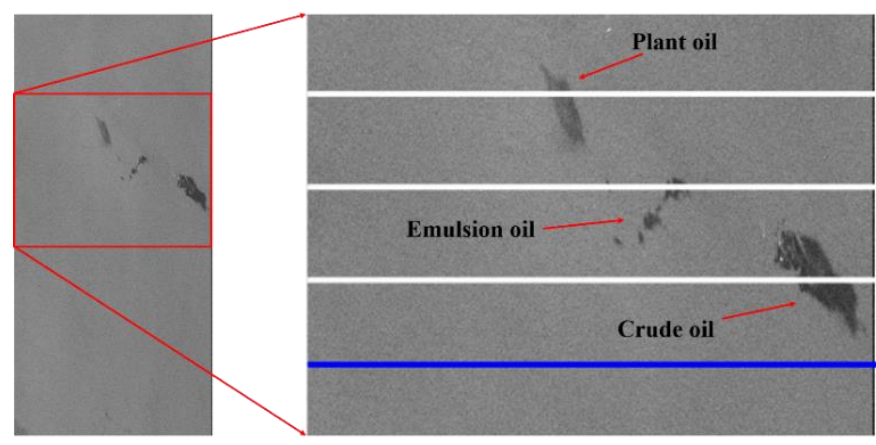

Figure 6. The Radarsat-2 SAR image used in this work. The three dark areas correspond to biological slick (upper left), emulsion oil (middle), and crude oil (lower right), respectively.

It is well known that a sea surface covered by the oil spill appears as a "dark patch" in the SAR image. One reason is that the backscattered power of the oil film-covered area becomes smaller due to the suppressed small-scale waves by the oil film. Another reason is 
that oil films with a smaller dielectric constant will also weaken the radar backscattering. In recent studies, the use of SAR images to extract the oil-water mixture ratio or the dielectric property of the oil-covered area has attracted more and more attention [40-42]. When the Bragg scattering dominates at a medium incident angle, the co-polarization ratio (HH/VV) is independent of the wave spectrum but depends on the dielectric properties of the sea surface. Thus, the polarization ratio obtained from SAR images can be utilized to retrieve the dielectric property.

However, the method based on the co-polarization ratio has a flaw that can't be ignored when the oil film is too thin. To make the dielectric constant have a non-negligible effect on radar scattering, the thickness of the oil layer must exceed 1/10 of the penetration depth, such as the oil layer thickness must be greater than $1 \mathrm{~mm}$ for the C-band SAR, and the oil layer thickness must be greater than $4 \mathrm{~mm}$ for L band SAR [43]. For a very thin oil film covering the sea surface (for example, a biological oil film, whose thickness is usually the thickness of a molecular layer; that is, only a few $10^{-9} \mathrm{~m}$ ), the dielectric constant of the oil film is much smaller than that of the seawater, resulting in the easy penetration of the microwave through the oil film. In other words, the change in the dielectric constant of the sea surface caused by the oil film can be ignored in this case. Meanwhile, according to the Bragg scattering theory, the polarization ratio of a sea surface covered by the thin oil film should be the same as that of a clean sea.

Figure 7 presents the co-polarization ratio estimated from the Radarsat- 2 image. The co-polarization ratio of the monomolecular biogenic oil film is significantly larger than that of a clean sea, which is inconsistent with the prediction of the classic Bragg theory. This inconsistency is attributed to the effect caused by non-Bragg scattering. Moreover, the existence of non-Bragg scattering on the oil film-covered sea surface will also cause errors in the inversion of dielectric constants of the area covered by oil film using the polarization ratio. Therefore, the non-Bragg scattering has a non-negligible influence on radar scattering of sea surface, which is consistent with the experimental result [34]. In the following, we will quantitative study the effect of non-Bragg scattering on total NRCS for the oil film-covered sea surface.

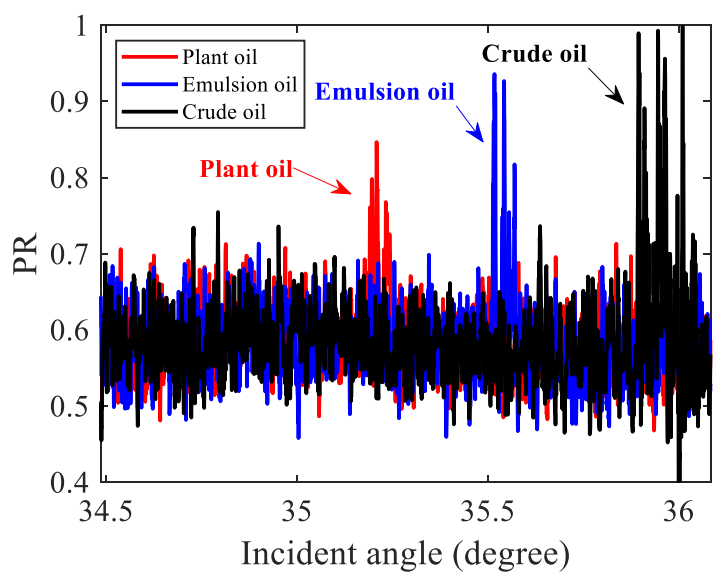

Figure 7. The co-polarization ratio extracted from the three white lines in Figure 6.

Figure 8 displays the "pure" Bragg waves spectra inverted from the three white lines in Figure 6. It is clearly seen that the spectral energy of the oil-covered area is significantly smaller than that of the clean sea surface due to the damping effect caused by oil films. Besides, the damping effect caused by the biological oil film is the smallest and then in increasing order are the emulsion oil and crude oil, mainly because of the different physical properties for these three kinds of oils. Hansen et al. studied the influences of various surface film elasticities on the effective viscosity coefficient and sea spectrum through theoretical simulation [29]. As stated in [29], the damping effect caused by oil film highly 
depends on the film elasticity. The different damping effect of plant oil, emulsion oil, and crude oil is induced by the differences in the elasticity of these three kinds of oil films.

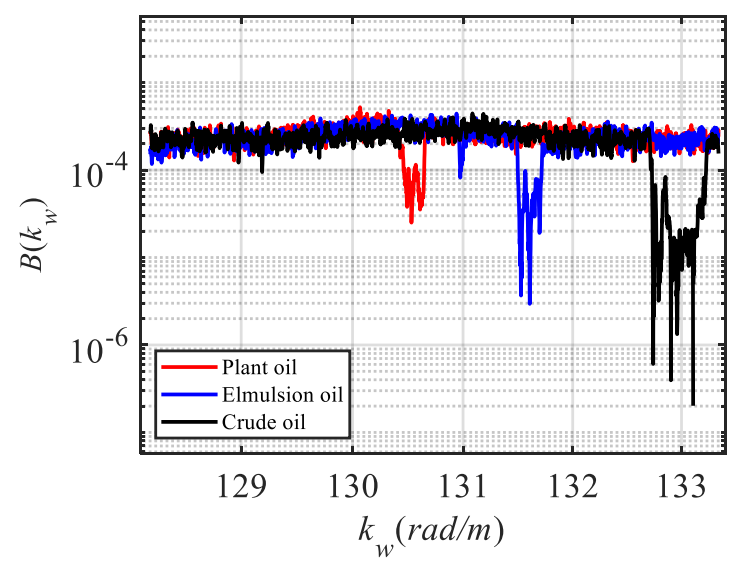

Figure 8. The "pure" Bragg wave curvature spectrum inverted from the three white lines in Figure 6.

Hansen et al. [29] studied the contrasts of the HH NRCS, VV NRCS, polarization difference, polarization ratio, the non-polarized component of different slicks. It was found that the contrast of non-Bragg scattering is significant and the non-Bragg scattering contribution is sensitive to the oil film type. Here, in Figure 9, we present the NRCSs of total scattering, "pure" Bragg scattering, non-Bragg scattering, and the relative contribution of non-Bragg scattering for three kinds of oil films. The NRCSs of total scattering were extracted from the three white lines in Figure 6. The NRCSs of non-Bragg scattering were calculated using Equation (9). Then, the NRCSs of "pure" Bragg scattering could be obtained by calculating the NRCSs differences of the total scattering and non-Bragg scattering. In Figure 9, for clean sea surface, the non-Bragg scattering amounts to about $40 \%$ for VV polarization, while it can account for about $70 \%$ for $\mathrm{HH}$ polarization, which is consistent with the results exhibited in Figure 3a. For oil-covered sea surfaces, the non-Bragg scattering is similar to the Bragg scattering for VV polarization (shown in Figure $9 \mathrm{a}, \mathrm{d}, \mathrm{g}$ ), while the non-Bragg scattering is larger than the Bragg scattering for $\mathrm{HH}$ polarization (shown in Figure 9b,e,h). As shown in Figure 9a,b,d,e,g,h, the NRCS of nonBragg scattering is different for different kinds of oil film, which is consistent with the results presented in [29]. In Figure 9c,f,i, one can note that the relative contribution of nonBragg scattering of $\mathrm{HH}$ polarized echo is significantly larger than that of $\mathrm{VV}$ polarization.

Compared with a clean sea surface, the reductions in the Bragg and non-Bragg components of an oil-covered sea surface are respectively caused by the suppression of small-scale wind waves and the modification of micro-breaking of $\mathrm{cm}$-dm-scale waves. The microbreaking is related to non-linear features in the profile of decimeter-scale waves, such as bulges, toes, and parasitic capillary ripples [34,35]. The micro-breaking can be effectively suppressed by oil films. As shown in Figure 9, the relative contribution of the non-Bragg scattering of an oil-covered sea surface is significantly larger than that of a clean sea surface, where the biological oil film is the smallest, followed by the emulsion oil and crude oil. The reason for this phenomenon may be that the suppression of resonant Bragg cm-scale waves induced by the oil film is more significant than that of wave micro-breaking.

Apart from NRCS, we also analyzed the effect of non-Bragg scattering on multipolarization features. In Figure 10, three commonly used multi-polarization features are derived from Radarsat-2 SAR data and compared with the predicted results via Bragg scattering theory. The polarimetric entropy $\left(H_{p}\right)$ is a measure of the randomness of the scattering process [39]. In Figure 10a, the polarimetric entropy of the clean sea surface is significantly larger than that of "pure" Bragg scattering, indicating that non-Bragg scattering makes the scattering process more random. Moreover, the obviously increased entropy for oil film-covered areas compared with the clean sea surface suggests that a more 
complex scattering event may be found in the oil-covered areas, agreeing with the results demonstrated in [39]. The co-polarization correlation coefficient $(\rho)$ for the "pure" Bragg scattering is close to unity, indicating that $\mathrm{HH}$ and $\mathrm{VV}$ echoes are highly correlated (shown in Figure 10b) [39]. Comparing with the co-polarization correlation coefficient of the "pure" Bragg predicted in theory, the co-polarization correlation coefficient of the clean sea surface calculated based on the Radarsat-2 image is smaller, and is even smaller for the oil-covered sea surface. This is because the depolarization effects caused by non-Bragg scattering lead to lower values of the co-polarization correlation coefficient. From Figure 10c, the value of degree of polarization (DoP) is close to 1 for the "pure" Bragg and decreases for the clean sea surface, becoming significantly reduced when the oil film covers the sea surface [44]. The reason for this phenomenon is that the non-Bragg scattering will enhance the depolarization effect, resulting in the smaller value of the DoP [44]. Consequently, all results from Figure 10 indicate that the impact of oil film on non-Bragg scattering can be well reflected by multi-polarization features.
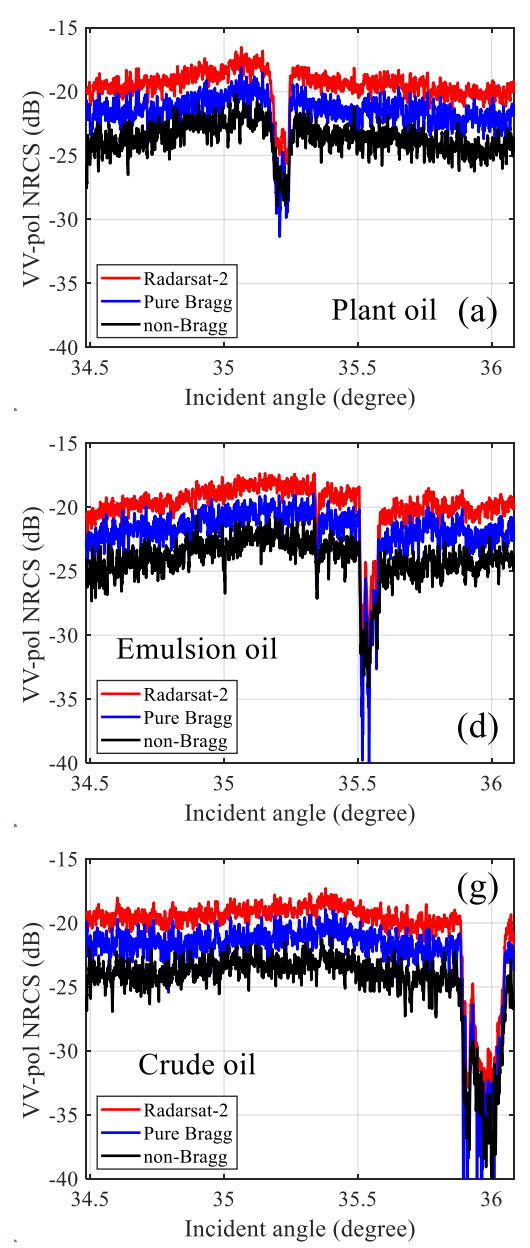
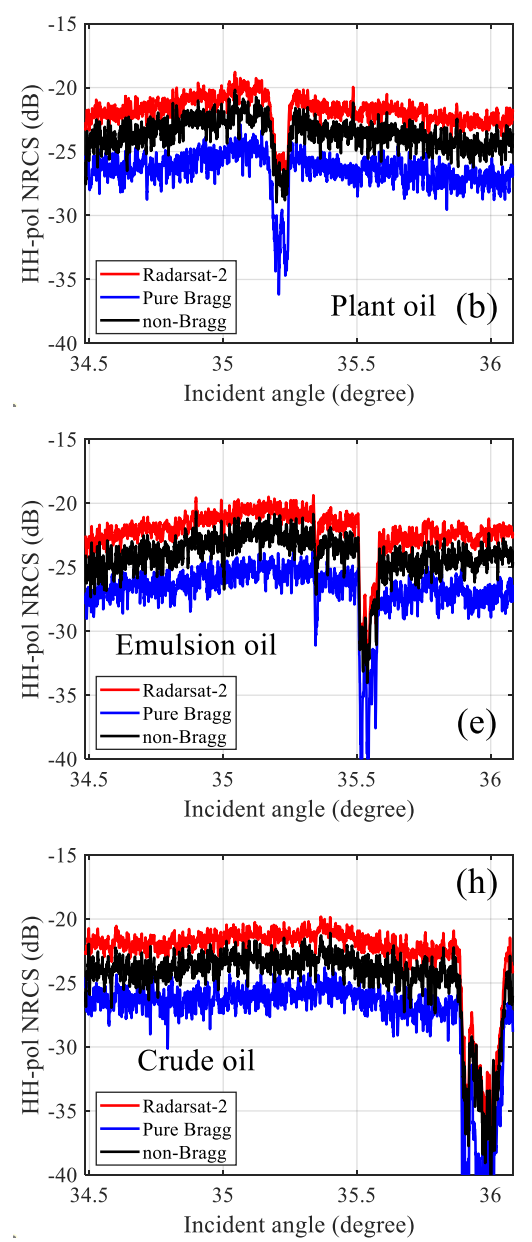
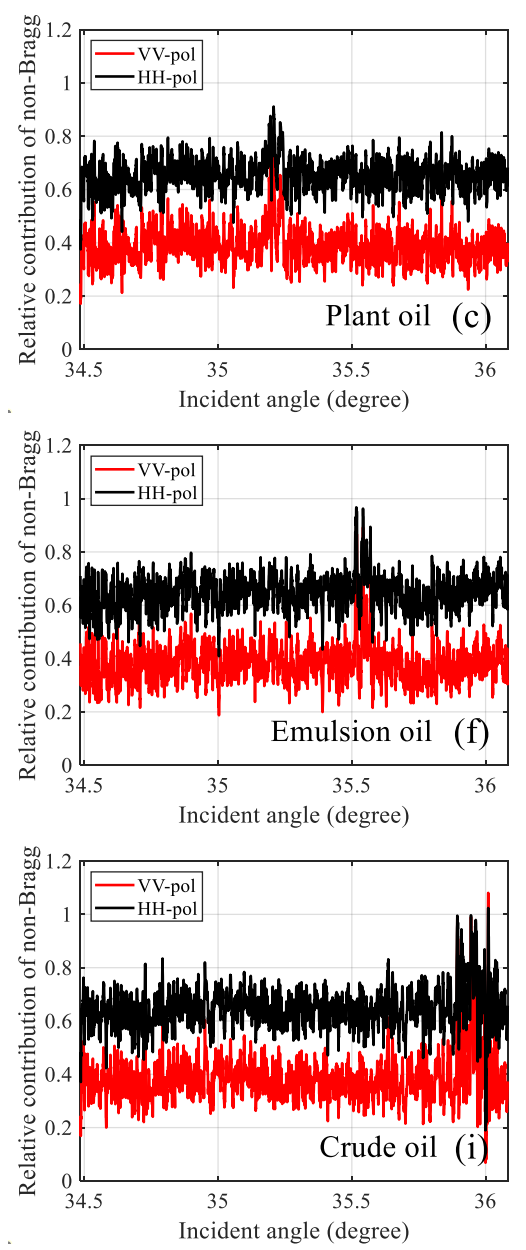

Figure 9. The NRCSs of total scattering, "pure" Bragg scattering and non-Bragg scattering, and the relative contribution of non-Bragg scattering for three kinds of oil films: (a-c) for plant oil, (d-f) for emulsion oil, (g-i) for crude oil. 

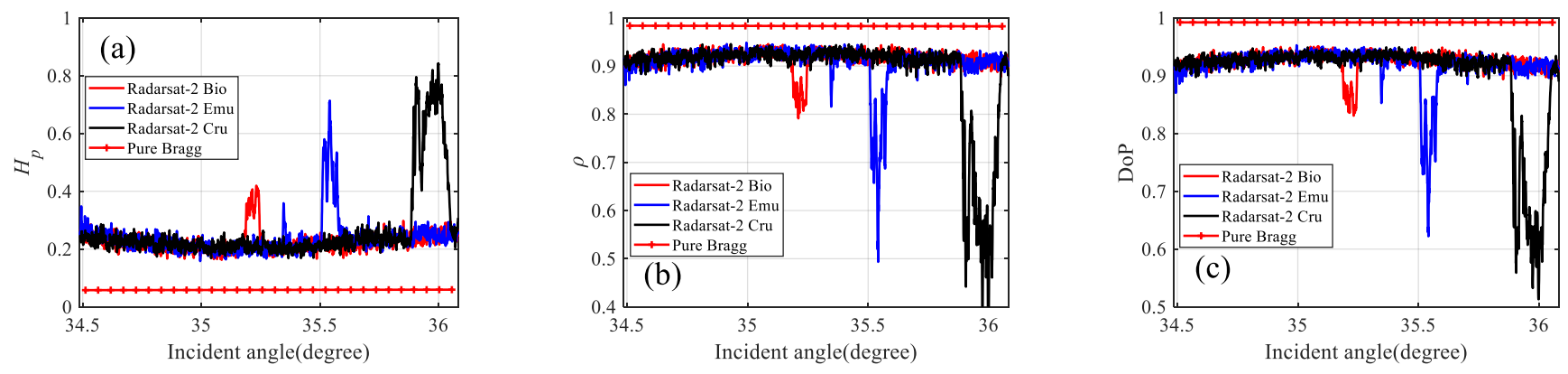

Figure 10. Comparisons of the multi-polarization features derived from the Radarsat-2 image with those predicted by Bragg scattering theory: (a) polarimetric entropy $\left(H_{p}\right),(\mathbf{b})$ the co-polarization correlation coefficient $(\rho)$, and (c) the degree of polarization (DoP).

\section{Conclusions and Perspective}

In the past several decades, the modeling of sea surface EM scattering has made significant progress, while the non-Bragg scattering is still not well understood. In this work, based on measured data and theoretical simulation, the influences of the nonBragg scattering on the microwave scattering from oil-free and oil-covered sea surfaces are discussed and analyzed in detail. The main contributions and conclusions can be summarized as follows:

(1) Through a systematic comparison of various sea spectra commonly used in the simulation of microwave scattering from clean sea surface, we find that the PD obtained from all discussed spectra are dramatically different from that from the GMFs, suggesting the inaccuracy of present sea spectra for modeling "pure" Bragg waves of oil-free sea surface. Thus, sea spectra more accurately describing Bragg waves are presented, which are calculated based on the TSM and GMFs.

(2) Quantitative investigation of the contribution of non-Bragg scattering under various incidence angles, wind directions, wind speeds, and radar frequencies is performed. We find that the non-Bragg scattering accounts for the largest proportion at crosswind direction comparing with upwind/downwind directions. Interestingly, the relative contribution of non-Bragg scattering is almost independent of wind speeds. Alongside this, it is also found that the higher frequency of radar waves, the larger relative contribution of non-Bragg scattering. Moreover, the results simulated by using XMOD2\&PR (shown in Figure 4) are not as good as those of CMODH (shown in Figure 3) and NSCAT4 (shown in Figure 5), which implies that a more accurate PR needs to be developed to achieve good enough results when using XMOD2\&PR to simulate the $\mathrm{X}$-band microwave scattering from sea surface.

(3) The presence of an oil film significantly impacts the Bragg sea waves and the nonBragg scattering. The suppressed effect for Bragg sea waves by biological oil film is the smallest and then in increasing order are emulsion oil and crude oil, which is due to the different damping abilities from different oil films. The same trend is also found for the relative contribution of non-Bragg scattering from sea surface covered with different oil films; namely, the order of the relative contribution of non-Bragg scattering for different oil films is biological oil $<$ emulsion oil $<$ crude oil.

(4) Three multi-polarization features widely used for detecting oil spills (i.e., polarimetric entropy, co-polarization correlation coefficient, degree of polarization) are derived from the Radarsat-2 image, which compares with those predicted by Bragg scattering theory. Comparing the results simulated by the Bragg theory, the polarimetric entropy becomes larger and the co-polarization correlation coefficient and the degree of polarization become smaller on the clean sea surface due to the existence of nonBragg scattering. Moreover, the floated oil films on the sea surface can increase the proportion of non-Bragg scattering, resulting in a larger polarimetric entropy, a lower co-polarization correlation coefficient, and a lower degree of polarization. Therefore, 
the influence of non-Bragg scattering on radar echoes can be well reflected by the multi-polarization features.

In conclusion, our work can not only provide some new insights for a better understanding of the non-Bragg microwave scattering at moderate incidence angles, but also provide theoretical guidance for using polarized SAR to detect oil spills on the sea surface. However, the conclusions drawn in this paper are inevitably affected by many factors (e.g., the inaccuracy of GMFs, the inaccuracy of first-order titled Bragg scattering theory, etc.). Only the cases for moderate incidence angles are studied, the scattering process may be more complex under large grazing angles. Additionally, only the cases for $\mathrm{C}_{-}, \mathrm{X}-$-, and $\mathrm{Ku}$-band radar scattering are adopted and studied in this work. In future works, large grazing angle cases and more frequencies and data will be considered to provide more detail and useful perspectives about the theoretical simulation, along with designing and conducting relevant field experiments to confirm the conclusions drawn in this work.

Author Contributions: Conceptualization, H.Z.; methodology, H.Z.; validation, H.Z. and X.-M.L.; investigation, H.Z.; writing—original draft preparation, H.Z.; writing—review and editing, J.Z., A.K. and X.-M.L. All authors have read and agreed to the published version of the manuscript.

Funding: This work was supported in part by the Joint Funds of the National Natural Science Foundation of China under Grant U2006207, the China Postdoctoral Science Foundation Funded Project under Grant 2020M682261, and the Fundamental Research Funds for the Central Universities under Grant 20CX06043A.

Data Availability Statement: The RADARSAT-2 SAR image was provided by Canadian Space Agency, which can be acquired from Earth Observation Data Management System (https: / / www. eodms-sgdot.nrcan-rncan.gc.ca).

Acknowledgments: The authors would like to thank Dan OUYANG for her useful advices on improving the quality of the manuscript.

Conflicts of Interest: The authors declare no conflict of interest.

\section{References}

1. Kudryavtsev, V.; Hauser, D.; Caudal, G.; Chapron, B. A semiempirical model of the normalized radar cross-section of the sea surface 1. Background model. J. Geophys. Res. Oceans 2003, 108, FET 2-1-FET 2-24. [CrossRef]

2. Wright, J.W. Backscattering from capillary waves with application to sea clutter. IEEE Trans. Antennas Propag. 1966, 14, 749-754. [CrossRef]

3. Churyumov, A.N.; Kravtsov, Y.A. Microwave backscatter from mesoscale breaking waves on the sea surface. Waves Random Media 2000, 10, 1-15. [CrossRef]

4. Kudryavtsev, V.N.; Fan, S.; Zhang, B.; Mouche, A.A.; Chapron, B. On quad-polarized SAR measurements of the ocean surface. IEEE Trans. Geosci. Remote Sens. 2019, 57, 8362-8370. [CrossRef]

5. Mouche, A.A.; Chapron, B.; Reul, N.; Hauser, D.; Quilfen, Y. Importance of the sea surface curvature to interpret the normalized radar cross section. J. Geophys. Res. Oceans 2007, C10002. [CrossRef]

6. Voronovich, A.; Zavorotny, V. Theoretical model for scattering of radar signals in $\mathrm{K}$ u-and C-bands from a rough sea surface with breaking waves. Waves Random Media 2001, 11, 247-269. [CrossRef]

7. Janssen, P.A.E.M.; Wallbrink, H.; Calkoen, C.J.; Halsema, D.V.; Oost, W.A.; Snoeij, P. VIERS-1 scatterometer model. J. Geophys. Res. 1998, 103, 7807-7830. [CrossRef]

8. Hwang, P.A.; Zhang, B.; Toporkov, J.V.; Perrie, W. Comparison of composite Bragg theory and quad-polarization radar backscatter from RADARSAT-2: With applications to wave breaking and high wind retrieval. J. Geophys. Res. Oceans 2010, 115, C11099. [CrossRef]

9. Zhang, B.; Zhao, X.; Perrie, W.; Kudryavtsev, V. On modeling of quad-polarization radar scattering from the ocean surface with breaking waves. J. Geophys. Res. Oceans 2020, 125. [CrossRef]

10. Kwoh, D.S.W.; Lake, B.M. A deterministic, coherent, and dual-polarized laboratory study of microwave backscattering from water waves, part I: Short gravity waves without wind. IEEE J. Ocean. Eng. 1985, 9, 291-308. [CrossRef]

11. Phillips, O. Radar returns from the sea surface-Bragg scattering and breaking waves. J. Phys. Oceanogr. 1988, 18, 1065-1074. [CrossRef]

12. Melville, W.K.; Loewen, M.R.; Felizardo, F.C.; Jessup, A.T.; Buckingham, M.J. Acoustic and microwave signatures of breaking waves. Nature 1988, 336, 54-56. [CrossRef]

13. Loewen, M.R. Microwave backscatter and acoustic radiation from breaking waves. J. Fluid Mech. 1991, 224, 601-623. [CrossRef] 
14. Plant, W.J.; Keller, W.C.; Hesany, V.; Hara, T.; Bock, E.J.; Donelan, M.A. Bound waves and Bragg scattering in a wind-wave tank. J. Geophys. Res. Oceans 1999, 104, 3243-3263. [CrossRef]

15. Plant, W.J. Microwave sea return at moderate to high incidence angles. Waves Random Media 2003, 13, 339-354. [CrossRef]

16. Fois, F.; Hoogeboom, P.; Le Chevalier, F.; Stoffelen, A. Future ocean scatterometry: On the use of cross-polar scattering to observe very high winds. IEEE Trans. Geosci. Remote Sens. 2015, 53, 5009-5020. [CrossRef]

17. Kudryavtsev, V.N.; Chapron, B.; Myasoedov, A.G.; Collard, F.; Johannessen, J.A. On dual co-polarized SAR measurements of the ocean surface. IEEE Geosci. Remote Sens. Lett. 2013, 10, 761-765. [CrossRef]

18. Fung, A.; Lee, K. A semi-empirical sea-spectrum model for scattering coefficient estimation. IEEE J. Ocean. Eng. 1982, 7, 166-176. [CrossRef]

19. Yurovsky, Y.Y.; Kudryavtsev, V.N.; Grodsky, S.A.; Chapron, B. Ka-band dual copolarized empirical model for the sea surface radar cross section. IEEE Trans. Geosci. Remote Sens. 2017, 55, 1629-1647. [CrossRef]

20. Cox, C.; Munk, W. Slopes of the sea surface deduced from photographs of sun glitter cox munk. Bull. Scripps Inst. Oceanogr. 1956, $6,401-488$.

21. Elfouhaily, T.; Chapron, B.; Katsaros, K.; Vandemark, D. A unified directional spectrum for long and short wind-driven waves. J. Geophys. Res. Oceans 1997, 102, 15781-15796. [CrossRef]

22. Hwang, P.A.; Sletten, M.A.; Toporkov, J.V. A note on Doppler processing of coherent radar backscatter from the water surface: With application to ocean surface wave measurements. J. Geophys. Res. Oceans 2010, 115, C03026. [CrossRef]

23. Hwang, P.A.; Burrage, D.M.; Wang, D.W.; Wesson, J.C. Ocean surface roughness spectrum in high wind condition for microwave backscatter and emission computations. J. Atmos. Ocean. Technol. 2013, 30, 2168-2188. [CrossRef]

24. Romeiser, R.; Alpers, W.; Wismann, V. An improved composite surface model for the radar backscattering cross section of the ocean surface: 1 . Theory of the model and optimization/validation by scatterometer data. J. Geophys. Res. Oceans 1997, 102, 25237-25250. [CrossRef]

25. Apel, J.R. An improved model of the ocean surface wave vector spectrum and its effects on radar backscatter. J. Geophys. Res. Oceans 1994, 99, 16269-16291. [CrossRef]

26. Pierson, W.J.; Moskowitz, L. A proposed spectral form for fully developed wind seas based on the similarity theory of S. J. Geophys. Res. Atmos. 1964, 69, 5181-5190. [CrossRef]

27. Zheng, H.; Khenchaf, A.; Wang, Y.; Ghanmi, H.; Zhang, Y.; Zhao, C. Sea surface monostatic and bistatic EM scattering using SSA-1 and UAVSAR data: Numerical evaluation and comparison using different sea spectra. Remote Sens. 2018, 10, 1084. [CrossRef]

28. Ryabkova, M.; Karaev, V.; Guo, J.; Titchenko, Y. A review of wave spectrum models as applied to the problem of radar probing of the sea surface. J. Geophys. Res. Oceans 2019, 124, 7104-7134. [CrossRef]

29. Hansen, M.W.; Kudryavtsev, V.; Chapron, B.; Brekke, C.; Johannessen, J.A. Wave breaking in slicks: Impacts on C-band quad-polarized SAR measurements. IEEE J. Sel. Top. Appl. Earth Observ. Remote Sens. 2016, 9, 4929-4940. [CrossRef]

30. Wentz, F.J.; Smith, D.K. A model function for the ocean-normalized radar cross section at 14 GHz derived from NSCAT observations. J. Geophys. Res. Oceans 1999, 104, 11499-11514. [CrossRef]

31. Li, X.-M.; Lehner, S. Algorithm for sea surface wind retrieval from TerraSAR-X and TanDEM-X data. IEEE Trans. Geosci. Remote Sens. 2013, 52, 2928-2939. [CrossRef]

32. Hersbach, H. CMOD5. N: A C-Band Geophysical Model Function for Equivalent Neutral Wind; European Centre for Medium-Range Weather Forecasts: Reading, UK, 2008.

33. Zhang, B.; Mouche, A.; Lu, Y.; Perrie, W.; Zhang, G. A geophysical model function for wind speed retrieval from C-band $\mathrm{HH}$-polarized synthetic aperture radar. IEEE Geosci. Remote Sens. Lett. 2019, 16, 1521-1525. [CrossRef]

34. Ermakov, S.A.; Sergievskaya, I.A.; Da Silva, J.C.B.; Kapustin, I.A.; Shomina, O.V.; Kupaev, A.V.; Molkov, A.A. Remote sensing of organic films on the water surface using dual co-polarized ship-based X-/C-/S-band radar and TerraSAR-X. Remote Sens. 2018, 10, 1097. [CrossRef]

35. Sergievskaya, I.A.; Ermakov, S.A.; Ermoshkin, A.V.; Kapustin, I.A.; Shomina, O.V.; Kupaev, A.V. The role of micro-breaking of small-scale wind waves in radar backscattering from sea surface. Remote Sens. 2020, 12, 4159. [CrossRef]

36. Isoguchi, O.; Shimada, M. An L-band ocean geophysical model function derived from PALSAR. IEEE Trans. Geosci. Remote Sens. 2009, 47, 1925-1936. [CrossRef]

37. Zhang, B.; Perrie, W.; He, Y. Wind speed retrieval from RADARSAT-2 quad-polarization images using a new polarization ratio model. J. Geophys. Res. Ocean 2011, 116, C08008. [CrossRef]

38. Monahan, E.C. Whitecaps and foam. Encycl. Ocean. Ences 2019, 3, $722-727$.

39. Skrunes, S.; Brekke, C.; Eltoft, T. Characterization of marine surface slicks by Radarsat-2 multipolarization features. IEEE Trans. Geosci. Remote Sens. 2014, 52, 5302-5319. [CrossRef]

40. Boisot, O.; Angelliaume, S.; Guérin, C. Marine oil slicks quantification from L-band dual-polarization SAR imagery. IEEE Trans. Geosci. Remote Sens. 2019, 57, 2187-2197. [CrossRef]

41. Li, H.; Perrie, W.; Wu, J. Retrieval of oil-water mixture ratio at ocean surface using compact polarimetry synthetic aperture radar. Remote Sens. 2019, 11, 816. [CrossRef]

42. Quigley, C.; Brekke, C.; Eltoft, T. Retrieval of marine surface slick dielectric properties from radarsat-2 data via a polarimetric Two-Scale Model. IEEE Trans. Geosci. Remote Sens. 2020, 58, 5162-5178. [CrossRef] 
43. Alpers, W.; Holt, B.; Zeng, K. Oil spill detection by imaging radars: Challenges and pitfalls. Remote Sens. Environ. 2017, 201, 133-147. [CrossRef]

44. Nunziata, F.; Gambardella, A.; Migliaccio, M. On the degree of polarization for SAR sea oil slick observation. ISPRS J. Photogramm. Remote Sens. 2013, 78, 41-49. [CrossRef] 